\title{
Foreword to Art Music by Caribbean Composers Volume 2
}

\section{Dominique-René de Lerma ${ }^{1}$}

Classical music has not traditionally been the domain of European musicians - although we have been led to believe that from publications, concerts, and text books. But it is not exclusively European property and was never claimed as such. This myth was perpetuated by the musicologists, who were also, not accidentally, European.

Nonetheless, the performance of music for an attentive audience who remained silent until the work was ended, is a concept rather antithetic to the purpose and function of music in many cultures, and remains so in many social environs. The preponderance of this music is improvised, or at least realised by the performer from a pre-existing source. That demands an ear and insight that is challenging and distinctive, but it does not allow for the creation of a work demanding more than momentary attention and instantaneous creation. If the musician seeks an extended form or wishes to give inner voices a more complex role, something else is needed. Polishing ideas in this manner can increase the time needed for the creation of the work. Once finished, it can be played outside of the immediate locale, its details are notated so that others may perform it, at a distance of space or time from the original creator.
When such a work is to be created in a new region, the composer may try to follow a European model, but this is dressing up one's own culture with foreign clothes. That is then the time to idealise the local impetus. In the United States, we struggled with this problem for decades, too few initially heeding the words of Antonín Dvořák when he was a visitor to New York in 1893. He had faced this situation when he tried to write music that reflected his own homeland, rather than the power of a German invasion. He urged the Americans not to follow Leipzig, but to acknowledge their distinctive roots. But these were the creation of slaves, at a time lynchings and minstrel shows were forms of popular entertainment. A few followed his advice: African Americans of course, like Harry Burleigh and William Grant Still with the spiritual and blues, and a few whose ancestry did not experience involuntary importation, George Gershwin, being the most successful.

When I was a guest of the College of The Virgin Islands more than 40 years ago, I heard someone lamenting publicly that they had never produced a Beethoven. True, but neither did Paris, London, or Oslo. I spoke with a student later and saw immediately that he had the same feeling of cultural inferiority. I asked if there was any music native to St.

\footnotetext{
${ }^{1}$ Dominique-René de Lerma, Professor Emeritus, Lawrence Conservatory of Music, Lawrence University, Appleton Wisconsin

E-mail: dsl@afgconsulting.org

APA reference: de Lerma, D.-R. (2013). Foreword to art music by Caribbean composers volume 2. The International Journal of Bahamian Studies, 19(2), i-iii. https://doi.or/10.15362/ijbs.v19i2.207
} 
Thomas. After a moment he mentioned that up in the hills there were lullabies mothers sang to their babies, but what his generation listened to were calypsos brought in from Trinidad, or pop music from the United States. My suggestion was not to continue regrets about the supposed absence of an immortal, but to be true to who the Islanders were, and build a national concert music that came up from their own experiences. Haiti, Puerto Rico, Brazil, and Cuba had learned this lesson many years earlier.

Gradually, the United States has begun to learn music that was not of European origin. We owe that discovery to ethnomusicologists who alerted the musicologists to humanism and social relevancy, who subsequently infected the educators and their students, from whom came those subversives who have begun to remove myopia from the repertoires. Now we are enjoying the richness of the music of contemporary Africa and Asia.

It might seem difficult to comprehend now, but there was a time when jazz could not be performed in the campus practice rooms, when no course was offered in the universities on American music. The change came about with the government funds made available to commemorate the Bicentennial of the United States in 1976. And money changed philosophies. Our own sentiments of cultural inferiority began to vanish and the repertoires and course offerings were augmented. In the end, if art music is the focus of attention, that study must be informed by all idioms.

All we in the United States might know now of The Bahamas and much of the Caribbean is tourism, adorned with a paternalistic attitude. So what message Dvořák offered over a century ago might relate to The Bahamas? What of the spirituals brought here by those immigrants who served the Loyalists? How has your music taken the British choral tradition as a point of departure? What dialect does your jazz speak? What of your traditional dances and your own lullabies? What of your folklore? That which is taking place now so dramatically in The Bahamas will further define classical music to the world. And herein are the means whereby these problems are addressed and these questions are answered.

Discoveries that are reported as a mere list of names are dead-end, providing no immediate amelioration. From this initial point, one needs to know what works these individuals have created, how to locate those that have been made available to the public, and which of these have been played or recorded. Now the work becomes functional for private collectors, libraries, and archives. Even this is not enough. The obligation now falls on those in a position to disseminate the information - authors, performers, educators, and those in the media. Simultaneously, the works must be seen in the light of the culture in which they were created and which they normally are designed to enhance. By that process, others develop a concept of the distinction of this culture and the people for whom it was created. The music now becomes securely located within the humanities and the culture gains a better understanding of humanity.

Outsiders may have been enchanted by beaches and breezes, perhaps previously unmindful that those who catered to their vacation stays had a life quite apart from contact with the visitors. They had experienced periods of colonialism, but meanwhile their individual identities had evolved, most often through a fusion of influences from Europe, Africa, Asia, and their own local original population.

Had anyone guessed there had been so many art composers, so prolific, from these 
countries? We knew about Christiane EdaPierre, the soprano born in 1932 in Martinique who captivated Parisian opera lovers; Edward Henry Margetson who migrated from St. Kitts to the United States, continuing his work in church music; baritone Willard White, born in Jamaica in 1948, who was knighted in 1995 by Queen Elizabeth II and ranks among the major artists of opera. What now of those others born in the Caribbean who enhanced not only their homeland, but also the musical life of London, New York, or Paris?

This pioneering work of Dr. Gangelhoff and Ms. LeGrand now creates opportunities for those who may hope to benefit from these efforts. J 